\title{
ESTAFILOCOCOS RESISTENTES À OXACILINA ISOLADOS EM CASOS DE MASTITE SUBCLÍNICA EM OVINOS
}

\author{
L.F. Zafalon ${ }^{1}$, C.J. Verissimo ${ }^{2}$, E.M. Mamizuka ${ }^{3}$, K.B. Martins ${ }^{1 *}$, L.M. Almeida ${ }^{2 * *}$, J.L.A. Veschii ${ }^{4}$ \\ 1Embrapa Pecuária Sudeste, CP339, CEP13560-970,São Carlos,SP, Brasil.E-mail: zafalon@cppse.embrapa.br
}

\section{RESUMO}

\begin{abstract}
Bactérias do gênero Staphylococcus estão entre os principais agentes causadores da mastite ovina. Um dos maiores entraves ao tratamento dos animais doentes são cepas resistentes aos antimicrobianos empregados. A pesquisa do gene mecA nos estafilococos é um instrumento auxiliar para a determinação de aspectos epidemiológicos da doença. Este trabalho teve por objetivo investigar a resistência à oxacilina em estafilococos coagulase-negativos isolados no leite de ovelhas com mastite subclínica. Foram analisadas 448 amostras de leite de dois rebanhos. Os micro-organismos isolados foram submetidos previamente a testes de sensibilidade a antibióticos in vitro a partir da técnica de difusão em disco. Naqueles resistentes à oxacilina nestes testes efetuou-se a pesquisa do gene mecA, com a extração do DNA cromossômico por meio da técnica de extração fenol-clorofórmio. Os estafilococos coagulase-negativos apresentaram resistência à oxacilina e a presença do gene mecA foi detectada em quatro isolados, que também apresentaram características de multirresistência. Tais achados reforçam a importância deste grupo de micro-organismos na etiologia da mastite subclínica em ovinos e abre perspectivas para futuras pesquisas para a investigação da epidemiologia da doença.
\end{abstract}

PALAVRAS-CHAVE: Staphylococcus spp., leite, gene mecA, resistência.

\begin{abstract}
OXACILLIN-RESISTANT STAPHYLOCOCCI ISOLATED FROM OVINE SUBCLINICAL MASTITIS. Staphylococcus bacteria are among the main agents of ovine mastitis. One of the greatest barriers to treatment of sick animals are strains resistant to antimicrobial agents. The research of the mecA gene in staphylococci is an auxiliary tool for the determination of epidemiological aspects of disease. The present study aimed to investigate oxacillin resistance in coagulase-negative staphylococci isolated in the milk from ewes with subclinical mastitis. A total of 448 samples from 2 flocks were analyzed. Colonies were previously submitted to testing for susceptibility to antibiotics in-vitro using the technique of disk diffusion. Using the oxacillin-resistant strains in these tests, the research of mecA gene was conducted with the extraction of chromosomal DNA by way of the technique of phenol-chloroform extraction. Coagulase-negative staphylococci were resistant to oxacillin, and the mecA gene was detected in 4 isolates, which also showed characteristics of multidrug resistance. These findings reinforce the importance of these microorganisms in the etiology of subclinical mastitis in ewes, and open perspectives for future research to investigate the epidemiology of this disease.
\end{abstract}

KEY WORDS: Staphylococcus spp, milk, mecA gene, resistance.

\section{INTRODUÇÃO}

A mastiteéuma inflamação da glândula mamária responsável por alterações físico-químicas e microbiológicas no leite, além de alterações no tecido glandular que afetam as células alveolares e ocasionam o comprometimento da produção de leite do animal (DOMINGUES et al., 2006).

A enfermidade, quando atinge os rebanhos ovinos, pode causar prejuízos econômicos por se tratar de uma doença relacionada com a mortalidade de ovelhas quando na forma clínica. Adicionalmente, a

${ }^{2}$ Instituto de Zootecnia, Nova Odessa, SP, Brasil.

${ }^{3}$ Universidade de São Paulo, Faculdade de Ciências Farmacêuticas, São Paulo, SP, Brasil.

${ }^{4}$ Embrapa Semiárido, Petrolina, PE, Brasil.

*Bolsista de Iniciação científica/Fapesp, Embrapa Pecuária Sudeste, São Carlos, SP.

**Doutoranda, Universidade de São Paulo, Faculdade de Ciências Farmacêuticas, São Paulo, SP. 
forma subclínica da doença interfere na viabilidade e no desempenho das crias, uma vez que há redução da concentração de imunoglobulinas no soro e da produção de leite, aumentando a mortalidade de cordeiros. A mastite, na dependência de sua etiologia infecciosa, pode causar quadros de toxinfecção ou desencadear infecções ou intoxicações no animal que ingereo leite (CLEMENTSet al., 2003; VAUTOR et al., 2005).

Staphylococcus aureus está entre os principais micro-organismos causadores da mastiteeéconsiderado importante patógeno em animais e humanos, por serem resistentes a antimicrobianos beta-lactâmicos, por exemplo, e possuírem um elemento genético móvel denominado Staphylococcus casset Chromossome mec (SCCmec), onde se encontra o gene mecA e seus reguladores que produzem a proteína ligadora de penicilina 2a (PBP2a) modificada que garante a resistência a todos os beta-lactâmicos (FITZGERALD et al., 2001; RICARDO, 2004). Na mastite ovina, porém, os estafilococos coagulase-negativos são prevalentes como agentes etiológicos da doença (LEITNER et al., 2003; CoutinHo et al., 2006). A relevância de Staphylococcus spp. é destacada, pois estão entre os agentes etiológicos mais frequentemente encontrados nos casos de mastite subclínica, variando entre 25 à 93\% dos isolados, além de causarem a forma clínica da doença, considerada mais grave ao estado geral do animal (BERGONIER et al., 2003).

Estafilococos coagulase negativa, assim como $S$. aureus, queé uma espécie coagulase positiva, podem apresentar elevadas taxas de resistência aos antimicrobianos, tais como a oxacilina (HUEBNER; GOLDMANN, 1999; Michelin et al., 2005), com a possibilidade de possuírem uma proteína ligadora de penicilina, com baixa afinidade em relação aos $\beta$-lactâmicos, codificada pelo gene mecA.

Oobjetivo deste estudo foi investigar a resistência à oxacilina em estafilococos coagulase-negativos isolados no leite de ovelhas com mastite subclínica, uma vez que poucas informações estão disponíveis acerca das características dos micro-organismos envolvidos na etiologia infecciosa da doença em ovinos.

\section{MATERIAL E MÉTODOS}

As amostras de leite foram obtidas na segunda semana de lactação e no dia em que ocorreu o desmame dos cordeiros, de cada mama ovina proveniente de 112 animais de dois rebanhos experimentais da raça Santa Inês, não destinados à produção comercial de leite, localizados nas cidades de Nova Odessa ( $\mathrm{n}=$ 36) e São Carlos ( $n=76)$, Estado de São Paulo, totalizando 448 amostras nos dois períodos de colheita.

Inicialmente, as mamas foram consideradas positivas para mastite subclínica quando identificadas reações à prova do California Mastitis Test
(CMT), representadas pelo aumento da viscosidade da mistura do leite com o reagente CMT (SCHALM; NOORLANDER, 1957), antes da colheita das amostras de leite para os exames microbiológicos. Os isolamentos dos microrganismos causadores de mastite foram utilizados para a confirmação dos casos da doença.

As colheitas das amostras para os exames microbiológicos foram realizadas após prévia antissepsia dos óstios papilares das mamas ovinas com algodão embebido com álcool etílico $70 \%$ (v/v). Após esse procedimento, cerca de $10 \mathrm{~mL}$ de leite das duas metades mamárias foram ordenhados, individualmente, em tubos de vidro com tampas rosqueáveis esterilizados, em duplicatas.

Após as colheitas, 144 amostras de leite originadas do rebanho ovino da Cidade de Nova Odessa foram congeladas a $-20^{\circ} \mathrm{Ce}$, posteriormente, encaminhadas para análises aos laboratórios da Embrapa Pecuária Sudeste, em São Carlos. As amostras de leite restantes, obtidas a partir do rebanho ovino de São Carlos foram enviadas imediatamente aos laboratórios e congeladas nas mesmas condições mencionadas anteriormente, quando não submetidas às provas de identificação microbiológica de forma imediata. Semeaduras de $10 \mu \mathrm{L}$ de leite de cada mama ovina foram realizadas sobre ágar Mueller-Hinton adicionado de sangue ovino a $5 \%$. As amostras foram incubadas a $37^{\circ} \mathrm{C}$ durante 24 a 48 horas para a posterior identificação dos micro-organismos.

As colônias classificadas como cocos Grampositivos foram submetidas às provas da catalase e da coagulase livre (Koneman, 2001). Aquelas que apresentaram resultados positivos nessas provas foram submetidas aos testes para verificação da produção de acetoína e utilização ou não da maltose e trealose. Os micro-organismos positivos nestas provas foram classificados como S. aureus, enquanto os negativos foram identificados como outros estafilococos coagulase-positivos. Os micro-organismos negativos à prova da coagulase foram submetidos a testes de resistência à novobiocina e classificados como estafilococos coagulase-negativos resistentes ou sensíveis à novobiocina (Holt et al., 1994; ZAFALON, 2003).

Os estafilococos isolados foram submetidos aos testes de sensibilidade in vitro utilizando-se a técnica de difusão em disco, frente a 12 antimicrobianos representados pela rifampicina $(30 \mu \mathrm{g})$, cloranfenicol $(10 \mu \mathrm{g})$, vancomicina $(30 \mu \mathrm{g})$, clindamicina $(2 \mu \mathrm{g})$, eritromicina $(15 \mu \mathrm{g})$, penicilina (10 UI), oxacilina $(1 \mu \mathrm{g})$, cefepima $(30 \mu \mathrm{g})$, tetraciclina (30 $\mu \mathrm{g})$, gentamicina $(10 \mu \mathrm{g})$, ciprofloxacina $(5 \mu \mathrm{g})$ e sulfametoxazol $(25 \mu \mathrm{g})$. A pós 24 horas de incubação a $35^{\circ} \mathrm{C}$, efetuou-se a aferição dos halos de inibição formados em torno dos respectivos princípios ativos, segundo o National Committee for Clinical LABORATORY STANDARDS (2005). 
Tabela 1 - Oligonucleotídeos iniciadores utilizados na amplificação de fragmento do gene mecA (Tamanho do fragmento igual a 200pb).

\begin{tabular}{lll}
\hline Gene alvo & Iniciador & Sequência de nucleotídeos \\
\hline & $\mathrm{mA1}$ & $5^{\prime}-$ TGC TAT CCA CCC TCA AAC AGG - 3' \\
mecA & $\mathrm{mA2}$ & $5^{\prime}-$ AAC GTT GTA ACC ACC CCA AGA - 3' \\
\hline
\end{tabular}

OKUмA et al. (2002).

A determinação da concentração inibitória mínima (CIM) para a oxacilina foi realizada pela técnica de Etest (AB Biodisk, Solna, Suécia). Após novo cultivo em ágar sangue ovino, uma colônia foi inoculada em caldo Müeller-Hinton e incubada a $37^{\circ}$ $C$ até que a suspensão bacteriana atingisse a escala 0,5 de McFarland. Um inóculo dessa suspensão foi aplicado em ágar Müeller-Hinton por meio de um swab e a fita de Etest com diferentes concentrações de oxacilina foi colocada sobre o meio já inoculado. As placas foram incubadas a $35^{\circ} \mathrm{C}$ por $24 \mathrm{~h}$. A leitura foi realizada conforme as instruções do fabricante e a interpretação dos resultados segundo o CLINICAL... (2007). Como controles foram utilizados S. aureus N315 e ATCC 25923, resistente e sensível à oxacilina, respectivamente.

O DNA cromossômico dos micro-organismos isolados foi extraído por meio da técnica de extração fenol-clorofórmio. Eles foram cultivados "overnight" em ágar LB e ressuspendidas em tampão de lise (50 $\mathrm{nM}$ Tris, $\mathrm{pH} 8,5 \mathrm{mM}$ EDTA $\mathrm{pH} 8,50 \mathrm{mM}$ $\mathrm{NaCl}$ ). A lisostafina (concentração final de $20 \mathrm{mg} / \mathrm{L}$ ) foi utilizada para a fase de rompimento das células. Proteinase $\mathrm{K}$ foi utilizada para a lise das proteínas, queforam removidas do meio por separação de fases com fenol-clorofórmio-álcool isoamílico. O DNA restante na fase aquosa foi precipitado com etanol absoluto gelado e centrifugado no equipamento Sorvall RC2-B (rotor SS34), aderindo à parede do tubo. Posteriormente, foi solubilizado em tampão TE (10 mM Tris, 1 mM EDTA, pH 8) e armazenado a $-20^{\circ} \mathrm{C}$.

A quantificação do DNA e sua integridade foram verificadas por eletroforese em gel de agarose $1 \%$, comparando-se com um padrão de massa molecular conhecido (High DNA Mass ${ }^{\mathrm{TM}}$ Ladder - Invitrogen ${ }^{\mathrm{TM}}$ ). O gel foi corado com solução de brometo de etídio (Invitrogen $^{\mathrm{TM}}$ ) na concentração final de $0,5 \mu \mathrm{g} / \mathrm{mL}$ e as bandas foram visualizadas sob luz ultravioleta.

Foi utilizado um par de iniciadores (ОкuмA et al., 2002), conforme demonstrado na Tabela 1 , para a amplificação do gene mecA (200 pb). Como controles foram utilizadas as cepas-padrão S. aureus ATCC 25.923, controle negativo, e S. aureus NCTC 85/2082, controle positivo.

Para amplificação do gene mecA foi utilizado o seguinte protocolo descrito por ОкUмА et al. (2002): um volume final de $20 \mathrm{~mL}$ de uma mistura para reação contendo $2 \mathrm{~mL}$ de DNA, 0,5 unidade de Taq polimerase, $2,5 \mathrm{~mL}$ do tampão concentrado fornecido com a enzima, os seguintes reagentes com suas respectivas concentrações finais: $\mathrm{MgCl} 2$ a 2,5 mM, cada dNTPa $200 \mathrm{mMe}$ os iniciadores a $250 \mathrm{nM}$. As reações foram executadas no termociclador Perkin-Elmer Gene Amp 2400 segundo as seguintes condições: um ciclo de cinco minutos a $94^{\circ} \mathrm{C}$ seguido de trinta ciclos de amplificação, cada um consistindo de 30 segundos a $95^{\circ} \mathrm{C}$, um minuto a $50^{\circ} \mathrm{C}$ e um minuto a $72^{\circ} \mathrm{C}$. A reação foi concluída com um ciclo de cinco minutos a $72^{\circ} \mathrm{C}$. Os produtos amplificados foram visualizados em gel de agarose corado com solução de brometo de etídio (Invitrogen ${ }^{\mathrm{TM}}$ ) na concentração final de $0,5 \mu \mathrm{g} / \mathrm{mL}$ e as bandas foram visualizadas sob luz ultravioleta.

Este trabalho foi realizado conforme os princípios éticos da experimentação animal estabelecidos pela EMBRAPA Pecuária Sudeste conforme consta em declaração emitida pelo Presidente da Comissão de Ética no Uso de Animais em 15/12/2008.

\section{RESULTADOS E DISCUSSÃO}

Foram obtidas 448 amostras de leite oriundas de 224 mamas de 112 animais em dois períodos distintos para a investigação da etiologia infecciosa da mastite ovina nos rebanhos, dentre as quais 105 amostras $(23,4 \%)$ originaram isolamentos e identificação de micro-organismos (Tabela 2).

Tabela 2 - Etiologia infecciosa da mastite ovina em dois rebanhos ovinos localizados no Estado deSão Paulo, 2011.

\begin{tabular}{lcc}
\hline Micro-organismos & No $^{\circ}$ isolamentos & $\%$ \\
\hline ECNSN $^{1}$ & 56 & 12,5 \\
ECNRN $^{2}$ & 19 & 4,2 \\
Staphylococcus aureus $^{3}$ & 10 & 2,2 \\
Outros ECP & 4 & 0,9 \\
Outros micro-organismos & 16 & 3,6 \\
Amostras de leite negativas & 343 & 76,6 \\
\hline Total de amostras & 448 & 100,0 \\
\hline
\end{tabular}

${ }^{1}$ Estafilococos coagulase-negativos sensíveis à novobiocina.

${ }^{2}$ Estafilococos coagulase-negativos resistentes à novobiocina.

${ }^{3}$ Estafilococos coagulase-positivos. 
Estafilococos coagulase-negativos sensíveis à novobiocina foram os micro-organismos de maior ocorrência $(12,5 \%)$, seguidos por estafilococos coagulasenegativos resistentes à novobiocina $(4,2 \%)$, S. aureus $(2,2 \%)$ e estafilococos coagulase-positivos $(0,9 \%)$. Outros micro-organismos diferentes de estafilococos foram isolados em 3,6\% das amostras de leite. Estes resultados foram semelhantes aos apresentados por Pengov (2001) que, dentre 496 amostras analisadas, encontrou estafilococos coagulase-negativos como os micro-organismos prevalentes $(18,0 \%)$, seguidos por $S$. aureus $(2,0 \%)$ e outras bactérias do gênero Staphylococcus $(1,4 \%)$

$\mathrm{O}$ teste de resistência à novobiocina foi usado no passado para a identificação presuntiva de $S$. saprophyticus, embora outras espécies de estafilococos negativos na prova da coagulase sejam resistentes à novobiocina. A sensibilidade/resistência à novobiocina é mencionada como um critério associado com a patogenicidade estafilocócica, uma vez que os isolados com sensibilidade à novobiocina têm sido descritos como responsáveis por alterações clínicas da mama, diferentemente dos resistentes à novobiocina, talvez por certas espécies classificadas de acordo com a resistência/sensibilidade à novobiocina apresentarem-se ou não mais patogênicas em função de seus fatores de virulência. A maior ocorrência dos estafilococos com sensibilidade à novobiocina, quando comparados com os resistentes a este princípio ativo, também foi relatada por outros autores (ARIZNABARRETA et al., 2002; GONZALO et al., 2002).

As características de sensibilidade e resistência de estafilococos coagulase-negativos aos antimicrobianos estão apresentados na Tabela 3.

A maioria dos estafilococos coagulase-negativos foram sensíveis aos princípios ativos empregados. A penicilina e a oxacilina foram os princípios em que ocorreram os maiores percentuais de resistência in vitro, $30,7 \%$ e $21,3 \%$, respectivamente, superiores a percentuais relatados na Bahia, também para ovelhas da raça Santa Inês com mastite subclínica, igual a 5,3\% para a penicilina e ausência de resistência para a oxacilina, apesar do relato de isolados que se apresentaram parcialmente sensíveis à oxacilina (CoutinHo et al., 2006). Em Botucatu, São Paulo, a sensibilidade de estafilococos coagulase-negativos à oxacilina de $58 \%$ em testes de disco-difusão foi inferior à encontrada no presente trabalho (Domingues et al., 2006).

Na Tabela 4 é possível visualizar os resultados, em conjunto, dos testes de disco-difusão, concentração mínima inibitória e de pesquisa da presença do gene mecA, referentes aos estafilococos coagulasenegativos resistentes à oxacilina.

Tabela 3 - Percentuais de suscetibilidade de estafilococos coagulase-negativos isolados no leite de ovelhas com mastite.

\begin{tabular}{|c|c|c|c|c|c|c|}
\hline \multirow{3}{*}{ Princípios ativos } & \multicolumn{6}{|c|}{ Micro-organismos } \\
\hline & \multicolumn{2}{|c|}{ Sensíveis } & \multicolumn{2}{|c|}{ Sensibilidade intermediária } & \multicolumn{2}{|c|}{ Resistentes } \\
\hline & $\mathrm{n}$ & $(\%)$ & $\mathrm{n}$ & $(\%)$ & $\mathrm{n}$ & $(\%)$ \\
\hline Rifampicina & 74 & 98,7 & 1 & 1,3 & 0 & 0,0 \\
\hline Sulfametoxazol & 74 & 98,7 & 0 & 0,0 & 1 & 1,3 \\
\hline Vancomicina $^{1}$ & 72 & 96,0 & - & - & - & - \\
\hline Cloranfenicol & 72 & 96,0 & 3 & 4,0 & 0 & 0,0 \\
\hline Gentamicina & 69 & 92,0 & 1 & 1,3 & 5 & 6,7 \\
\hline Tetraciclina & 68 & 90,6 & 5 & 6,7 & 2 & 2,7 \\
\hline Cefepima & 65 & 86,7 & 4 & 5,3 & 6 & 8,0 \\
\hline Clindamicina & 64 & 85,3 & 5 & 6,7 & 6 & 8,0 \\
\hline Ciprofloxacina & 62 & 82,7 & 12 & 16,0 & 1 & 1,3 \\
\hline Oxacilina & 59 & 78,7 & 0 & 0,0 & 16 & 21,3 \\
\hline Penicilina & 52 & 69,3 & 0 & 0,0 & 23 & 30,7 \\
\hline Eritromicina & 40 & 53,3 & 32 & 42,7 & 3 & 4,0 \\
\hline
\end{tabular}

${ }^{1}$ As três estirpes não suscetíveis ao teste de difusão em disco não foram submetidas a testes adicionais para confirmação de resistência.

“_” Ausência de resultados.

Tabela 4 - Estafilococos coagulase-negativos resistentes à oxacilina nas provas de disco-difusão e concentração inibitória mínima (Etest), isolados do leite de ovelhas com mastite.

\begin{tabular}{lcccc}
\hline Micro-organismos & $\mathrm{n}$ & Disco-difusão & Etest & Presença do gene mecA \\
\hline ECNRN $^{1}$ & $56(100 \%)$ & $12(21,4 \%)$ & $10(17,9 \%)$ & $4(7,1 \%)$ \\
ECNSN $^{2}$ & $19(100 \%)$ & $4(21,0 \%)$ & $1(5,3 \%)$ & $0(0,0 \%)$ \\
\hline Total & $75(100 \%)$ & $16(21,3 \%)$ & $11(14,7 \%)$ & $4(5,3 \%)$ \\
\hline
\end{tabular}


A resistência à oxacilina nos testes de halodifusão não foi observada em outros estafilococos, mas somente em estafilococos coagulase-negativos, correspondendo a um total de 16 isolados $(21,3 \%)$. Uma das modificações utilizadas na tentativa de aumentar a expressão de resistência à oxacilina é a realização de antibiogramas com incubação a $35^{\circ}$ $\mathrm{C}$, ao invés de $37^{\circ} \mathrm{C}$, o que pode ter colaborado na deteç̧ão dos isolados resistentes (MimicA; MENDES, 2007). Dentre 16 estafilococos coagulase-negativos resistentes à oxacilina nos testes de disco-difusão em ágar, 11 (68,8\%) apresentaram valores ao Etest condizentes com resistência à oxacilina e, dentre estas, quatro $(25,0 \%)$ foram mecA positivos.

Verificou-se maior número de micro-organismos resistentes à novobiocina com resistência à oxacilina, quando comparados com os estafilococos sensíveis à novobiocina que, por sua vez, foram os micro-organismos de maior ocorrência nos rebanhos quando comparados aos resistentes à novobiocina. Dentre 16 estafilococos coagulase-negativos isolados resistentes à oxacilina nos testes de discodifusão, 12 (75\%) foram resistentes à novobiocina, enquanto dos 11 resistentes após a realização do Etest, 10 (90,9\%) foram resistentes à novobiocina. Todas os micro-organismos positivos para o gene mecA foram resistentes à novobiocina. Ao Etest, um isolado sensível à novobiocina apresentou CIM à oxacilina igual a $0,75 \mu \mathrm{g} / \mathrm{mL}$, porém não foi classificado de acordo com a resistência a este antimicrobiano, pela não realização de provas para a diferenciação das espécies estafilocócicas. Caso este isolado fosse identificado como S. lugdunensis, a esta concentração seria considerado sensível à oxacilina. Por outro lado, se outra espécie, seria considerada resistente.

Desconhece-se a origem dos micro-organismosresistentes à oxacilina nos rebanhos ovinos do presente trabalho, porém a detecção de gene de resistência à oxacilina é relevante, uma vez que diferentemente da doença em bovinos, na mastite em ovelhas o uso de tratamento contra a doença com antimicrobianos é menos comum. Dentre quatro estafilococos coagulase-negativos mecA positivos, metade era oriunda de um dos rebanhos e o restante do outro e em nenhum dos dois rebanhos investigados havia a presença concomitante de vacas leiteiras e ovelhas. Entretanto, nos dois rebanhos, leite de vaca era fornecido aos cordeiros com dificuldade em mamar e houve a possibilidade desses cordeiros entrarem, no decorrer da lactação das ovelhas, em contato com as mamas ovinas na tentativa de se alimentarem. Em estudos anteriores (ARCARO et al., 2006; AlmEIDA, 2009), foi evidenciada a presença de estafilococos coagulase-negativos nos dois rebanhos bovinos leiteiros cujo leite foi fornecido aos cordeiros do presente estudo. Sugere-se a realização de outros trabalhos para decifrar possíveis inter-relações entre micro-organismos de diferentes espécies animais, principalmente entre ovinos e bovinos.

Por meio dos resultados dos testes moleculares foi possível observar que em sete isolados não foi detectado o gene mecA, o que sugere a existência de outros mecanismos de resistência à oxacilina por parte dos estafilococos, além daquela conferida pelo $m e c \mathrm{~A}$. Dentre os sete isolados resistentes à oxacilina pelo Etest, sem a detecção do gene mecA, três apresentaram um nível de resistência "borderline" baseado nos resultados do Etest. Testes adicionais não foram realizados, mas sugere-se que estes isolados possam ser hiperprodutores de beta-lactamase ou apresentam mecanismos de resistência adicional, como sugerido também por MARTINEAU et al. (2000) e TERASAWA (2006). O gene femB, por exemplo, está envolvido no metabolismo da parece celular bacteriana, codifica proteínas que influenciam no nível de resistência de estafilococos à oxacilina e é comum a todas as espécies de Staphylococcus e também responsável pelo grau de resistência a este antibiótico (SANTOS et al., 2005). Esses autores estudaram a presença dos genes mecA e fem $\mathrm{B}$ em dezessete $S$. aureus resistentes à oxacilina e relataram a presença do gene $f e m \mathrm{~B} e m$ todas as estirpes estudadas, enquanto o gene mecA não foi encontrado em nenhuma. Diferentemente, STROMMENGER et al. (2003) encontraram o gene mecA em 28 isolados classificados como $S$. aureus resistentes à oxacilina.

Micro-organismos resistentes à oxacilina apresentaram maior resistência frente a outros antibióticos, principalmente à penicilina, cefepima e gentamicina, quando comparados com os demais micro-organismos sensíveis à oxacilina. Resultados semelhantes de multirresistência foram verificados por TuRutoglu et al. (2006), que detectaram S. aureus e estafilococos coagulase-negativos fenotipicamente resistentes à oxacilina, dentre os quais $100 \%$ dos S. aureus foram também resistentes à penicilina $G$, amoxicilina, cloxacina e gentamicina. Quanto aos estafilococos coagulase-negativos, todos foram resistentes à penicilina $G$, amoxicilina, enquanto $96,8 \%$ foram resistentes à cloxacina.

Mais estudos poderão ser feitos decorrentes dos achados do presente trabalho, sobretudo relacionados à origem dos isolados resistentes à oxacilina obtidos a partir do leite das ovelhas, abrindo perspectivas para a investigação da epidemiologia da doença em ovinos.

\section{CONCLUSÕES}

A presença de estafilococos coagulase-negativos resistentes à oxacilina em casos de mastite em animais não destinados à produção comercial de leite 
atesta a relevância destes microrganismos na mastite ovina. A detecção do gene mecA e a multirresistência encontrada em estafilococos coagulase-negativos reforça a importância do uso consciente de medidas de controle contra a doença, tais como o tratamento com antimicrobianos.

\section{AGRADECIMENTOS}

À Fundação de Amparo à Pesquisa do Estado de São Paulo/FAPESP - Processo no 2007/56558-9.

\section{REFERÊNCIAS}

ALMEIDA, L.A.B. Avaliação de tratamento homeopático com Phytolacca decandra 30 ch durante a lactação de vacas com mastite subclínica. 2009. 93p. Tese (Doutorado em Epidemiologia Experimental Aplicada às Zoonoses) Faculdade de Medicina Veterinária e Zootecnia, Universidade de São Paulo, USP, São Paulo, 2009.

ARCARO, J.R.P.; ARCARO, I.; POZZI, C.R.; MATARAZZO, S.V.; FAGUNDES, H.; ZAFALON, L.F.; COSTA, E.O. Climatização em instalação do tipo free-stall: comportamento animal e ocorrência de mastite em vacas em lactação. Napgama, v.9, n.1, p.3-6, 2006.

ARIZNABARRETA, A.; GONZALO, C.; PRIMITIVO, F.S. Microbiological quality and somatic cell count of ewe milk with special reference to Staphylococci. Journal of Dairy Science, v.85, n.6, p.1370-1375, 2002.

BERGONIER, D.; CRÉMOUX, R. de.; RUPP, R.; LAGRIFFOUL, G.; BERTHELOT, X. Mastitis of dairy small ruminants. Veterinary Research, v.34, p.689-716, 2003.

CLEMENTS, A.C.A.; TAYLOR, D.J.; FITZPATRICK, J.L. Evaluation of diagnostic procedures for subclinical mastitis in meat-producing sheep. Journal of Dairy Research, v.70, p.139-148, 2003.

CLINICAL LABORATORY STANDARDS INSTITUTE. Performance Standards for antimicrobial susceptibility testing. Fifteenth Informational Supplement. Wayne: CLSI, 2005. 2005. (CLSI M100 - S15).

CLINICAL LABORATORY STANDARDS INSTITUTE. Clinical and laboratory standards institute. Performance Standards for Antimicrobial Susceptibility Testing. 17.ed. Wayne: CLSI/NCCS, 2007. (CLSI/NCCS M100 - S17).

COUTINHO, D.A.; COSTA, J.N.; RIBEIRO, M.G.; TORRES, J.A Etiologia e sensibilidade antimicrobiana in vitro de bactérias isoladas de ovelhas da raça Santa Inês com mastite subclínica. Revista Brasileira de Saúde e Produção Animal, v.7, n.2, p.139-151, 2006.

DOMINGUES, P.F.; LUCHEIS, S.B.; SERRÃO, L.S. FERNANDES, S.; CONTENTE, A.P.A.; MARTINS, E.C.V.;
LANGONI, H. Etiologia e sensibilidade bacteriana da mastite subclínica em ovelhas da raça Santa Inês. Ars Veterinaria, v.22, n.2, p.146-152, 2006.

FITZGERALD, J.R.; STURDEVANT, D.E.; MACKIE, S.M.; GILL, S.R.; MUSSER, J.M. Evolutionary genomics of Staphylococcus aureus: insights into the origin of methicillin-resistant strains and the toxic shock syndrome epidemic. Proceeding of the National Academy of Sciences, v.98, p.8821-8826, 2001.

GONZALO, C.; ARIZNABARRETA, A.; CARRIEDO, J.A.; PRIMITIVO, F.S. Mammary pathogens and their relationship to somatic cell count and milk yield losses in dairy ewes. Journal of Dairy Science, v.85, n.6, p.14601467, 2002.

HOLT, J.G.; KRIEG, N.R.; SNEATH, P.H.A.; STALEY, J.T.; WILLIAMS, S.T. Gram-positive cocci. In: (Ed.). Bergey's manual of determinative bacteriology. 9th.ed. Baltimore: Williams \& Wilkins, 1994. p.544-551.

HUEBNER, J.; GOLDMANN, D.A. Coagulase-negative staphylococci: role as pathogens. Annual Review of Medicine, v.50, p.223-236, 1999.

KONEMAN, E.W.; ALLEN, S.D.; JANDA, W.M.; SCHRECKENBERGER, P.C.; WINN JUNIOR, W.C.W. Diagnóstico microbiológico - Texto e atlas colorido. 5.ed. Rio de Janeiro: Medsi, 2001. 1465p.

LEITNER, G.; CHAFFER, M.; CARASO, Y.; EZRA, E.; KABABEA, D.; WINKLER, M.; GLICKMAN, A.; SARAN, A. Udder infection and milk somatic cell count, NAGase activity and milk compositionfat, protein and lactose-in Israeli-Assaf and Awassi sheep. Small Ruminant Research, v.49, p.157-164, 2003.

MARTINEAU, F.; PICARD, F.J.; LANSAC, N.; MÉNARD, C.; ROY, P.H.; OUELLETTE, M.; BERGERON, M.G. Correlation between the resistance genotype determined by multiplex PCR assays and the antibiotic susceptibility patterns of Staphylococcus aureus and Staphylococcus epidermidis. Antimicrobial Agents and Chemotherapy, v.44, n.2, p.231-238, 2000.

MICHELIN, L.; LAHUDE M.; ARAÚJO, P.R.; GIOVANAZ, D.S.H.; MÜLLER, G.; DELAMARE, A.P.L.; COSTA, S.O.P.; ECHEVERRIGARAY, S. Pathogenicity factors and antimicrobial resistance of Staphylococcus epidermidis associated with nosocomial infections occurring in intensive care units. Brazilian Journal of Microbiology, v. 36, p.17-23, 2005.

MIMICA M.J.; MENDES, C.M.F. Diagnóstico laboratorial da resistência à oxacilina em Staphylococcus aureus. Jornal Brasileiro de Patologia e Medicina Laboratorial, v.43, n.6, p.399-406, 2007. 
PENGOV, A. The role of coagulase-negative Staphylococcus spp. and associated somatic cell counts in the ovine mammary gland. Journal of Dairy Science, v.84, n.3, p.572-574, 2001.

OKUMA, K.; IWAKAWA, K.; TURNIDGE, J.D.; GRUBB, W.B.; BELL, J.M.; O'BRIEN, F.G.; COOMBS, G.W.; PEARMAN, J.W.; TENOVER, F.C.; KAPI, M.; TIENSASITORN, C.; ITO, T.; HIRAMATSU, K. Dissemination of new methicillin-resistant Staphylococcus aureus clones in the community. Journal of Clinical Microbiology, v.40, p.4289-4294, 2002.

RICARDO, S.B. Emergência de Staphylococcus aureus meticilina-resistentes (MERSA) na Comunidade. Prática Hospitalar, v6, n.34,2004.

SANTOS, F.G.B.; OLIVEIRA, W.L.M.; GARINO JÚNIOR, F.; LEAL, N.C.; COSTA, E.O.; LEAL BALBINO, T.C. Investigação dos mecanismos de resistência à oxacilina em Staphylococcus aureus isolados de casos de mastite bovina. Napgama, v.8, n.2, p.14-17, 2005.

SCHALM, O.W.; NOORLANDER, D.O. Experiments and observations leading to development of the California Mastitis Test. Journal of American Veterinary Medical Association, v.130, n.5, p.199-207, 1957.

STROMMENGER, B.; KETTLITZ, C.; WERNER, G.; WITTE, W. Multiplex PCR assay for simultaneous detection of nine clinically relevant antibiotic resistance genes in Staphylococcus aureus. Journal of Clinical Microbiology, v.41, n.9, p.4089-4094, 2003.

TERASAWA, L.B. Caracterização da resistência à oxacilina em estafilococos coagulase negativa isolados no hospital de clínicas de Curitiba - Paraná. 2006. 109p. Dissertação (Mestrado em Microbiologia, Parasitologia e Patologia) - Universidade Federal do Paraná, Curitiba, 2006.

TURUTOGLU, H.; ERCELIK, S.; OZTURK, D. Antibiotic resistance of Staphylococcus aureus and coagulase-negative Staphylococci isolated from bovine mastitis. Bulletin of the Veterinary Institute in Pulawy, v.50, p.41-45, 2006.

VAUTOR, E.; JAY, C.; CHEVALIER, N.; VISOMBLIN, N.; VERNET, G.; PÉPIN, M. Characterization of 26 isolates of Staphylococcus aureus, predominantly from dairy sheep, using four different techniques of molecular epidemiology. Journal of Veterinary Diagnostic Investigation, v.17, p.363-368, 2005.

ZAFALON, L.F. Mastite subclínica bovina por Staphylococcus aureus: qualidade e quantidade de leite secretado por quartos tratados e não tratados e relação custo/benefício do tratamento durante a lactação. 2003. 66p. Tese (Doutorado em Medicina Veterinária Preventiva) - Faculdade de Ciências Agrárias e Veterinárias, Universidade Estadual Paulista, Jaboticabal, 2003.

Recebido em 15/12/10

Aceito em 8/11/11 